\title{
ALCOHOL CONSUMPTION, SMOKING AND WAGES
}

Jenny N. Lye and Joe Hirschberg

\author{
Department of Economics \\ University of Melbourne \\ Parkville, Vic 3052 \\ jnlye@myriad.its.unimelb.edu.au
}

March 2000

\begin{abstract}
The good health of an individual is a combination of uncontrollable factors that includes genetics and random events and controllable factors through the regulation of activities such as smoking and drinking. Since the work of Grossman (1972) a significant relationship between health and earnings is predicted. In this paper the 1995 Australian National Health Survey is used to simultaneously examine the effects of drinking and smoking on wages. To model the interaction of smoking with alcohol consumption separate models are fit for smokers and nonsmokers. These models account for potential selectivity bias resulting from the decision to smoke and endogeneity arising from a potential causal relationship between earnings and alcohol consumption..
\end{abstract}

Key words: Alcohol Consumption; Smoking; Wages; Selectivity Bias; Instrumental variables 


\section{INTRODUCTION}

The good health of an individual is a combination of uncontrollable factors that includes genetics and random events and controllable factors through activities such as smoking and drinking. Grossman (1972) showed a significant relationship between health and earnings. In this paper we examine the impact of two indicators of health on wages. We examine drinking and smoking with special attention given to the nonlinearities and interactions of these activities on health as suggested in the medical literature. The salient features of the medical literature on these two activities and the interactions between them is summarized below. We also describe the literature which relates these activities to wages.

\subsection{Alcohol Consumption}

The (US) National Institute on Alcohol Abuse and Alcoholism (NIAAA 1997) has defined moderate drinking as no more than two standard drinks per day for a man age 65 or under, and no more than one standard drink per day for men over the age of 65 and all women ${ }^{1}$. The upper limit of moderate drinking is set lower for women because it has been found that the same amount of alcohol has a stronger effect in women due to differences in body size, body composition and the efficiency of alcohol metabolism ( NIAAA 1990, NIAAA 1997a, Goist and Sutker 1985, Frezza et al 1990) relative to men. The upper limit of moderate drinking has been set lower for men 65 and older because the amount of muscle tissue decreases with age so that consequently the same dose of alcohol produces a higher blood alcohol level ( NIAAA 1998). Moderate drinking is the only pattern of drinking that has been shown to have potential health benefits (ACSH 1999) $)^{2}$. In Australia while per capita consumption of alcohol has stabilised over recent years Australians remain the highest consumers of alcohol per person of any English speaking population, ranking fifteenth in the world (NHMRC 1992). In the 1995 Australian National Health survey $85 \%$ of people who 
drank alcohol in the reference week did so at levels considered to be of low risk to their health (NHS 1995).

Health problems associated with the excessive intake of alcohol include liver damage, heart disease, ulcers, cancers of the head and throat, alcoholism and impairment of mental functions. Overuse of alcohol has also shown to contribute to obesity and high blood pressure. Multiple studies in medical research ( Klatsky et al 1990; Rimm et al 1991; Jackson et al 1991; Razay et al 1992; DeLabry et al 1992; Coate 1993 ) have described a U-shaped relationship between alcohol consumption and risk of death from all causes. That is nondrinkers and heavy drinkers have an increased risk of death compared with moderate drinkers. This association is largely due to lower death rates from coronary heart disease among moderate drinkers ${ }^{3}$. The risk of cardiovascular mortality has been estimated to be between 45 and 80 per cent lower for a moderate consumer of alcohol than for either an abstainer or an abuser (Klatsky et al 1990). This relationship has been observed in both men and women and in different age, geographic, and ethnic groups (NIAAA 1997, Pearson 1996). It is also independent of other risk factors for heart disease such as smoking and obesity (Moore and Pearson 1986). In addition, all types of alcohol beverages are associated with reduced risk of coronary heart disease (Rimm et al 1996).

Explanations for moderate alcohol's cardioprotective effect include (see BaumBaicker 1985) an increase in the levels of high density lipoprotein cholesterol (HDL) which acts in the removal of cholesterol from tissue, associated diet changes in moderate drinkers, the silicon content in wine and beer, decreased platelet aggregation and coagulation, and the ability to lessen stress and alter personality patterns associated with coronary heart disease. In addition, Baum-Baicker (1985) report that heavy drinkers and abstainers suffer from higher rates of clinical depression than regular moderate drinkers. 
Recently there have been a number of studies that examine the relationship between alcohol use and labour market success. Drinking and labour market success have important life-cycle dimensions such that alcohol problems can adversely affect a person's future work for years (Mullahy and Sindelar 1993). Mullahy and Sindelar (1993) present evidence that alcoholism ${ }^{4}$ may affect income more by restricting labor-market participation than by affecting the wages of workers. Mullahy and Sindelar (1996) examine the relationship between measures of problem drinking ${ }^{5}$ and of employment and unemployment. The analysis is based on the 1988 Alcohol Supplement of the National Health Interview Survey. The authors find that, for both men and women, problem drinking results in reduced employment and increased unemployment.

A number of other studies have focussed on the relationship between alcohol consumption and earnings for those individuals with a relatively stable employment pattern. Berger and Leigh (1988) use data from the 1972-73 Quality of Employment Survey to estimate wage equations for drinkers and nondrinkers and a correction for selectivity bias resulting from the drinking decision is employed. They conclude that drinkers earn more than non-drinkers even after controlling for differences in observable characteristics and selectivity bias. Using data from the 1985 General Social Survey which contains data on a random sample of Canadians, Hamilton and Hamilton (1997) decompose the group of drinkers into heavy, moderate and light drinkers. They find that moderate alcohol consumption leads to increased earnings relative to abstention. However, heavy drinking leads to reduced earnings relative to moderate drinking. Heavy drinkers also receive lower returns to higher education than other drinker types. Barett (1999) obtained similar conclusions by replicating the analysis of Hamilton and Hamilton (1997) using data from the 1989 Australian Health survey. In an analysis of US workers Heien (1996) uses the 1979 and 1984 surveys from the National Household survey on Alcohol use. His results suggest that moderate drinkers earn more than 
either abstainers or abusive drinkers. French and Zarkin (1995) found that individuals who consume approximately 1.5 to 2.5 drinks per day have higher wages than non-drinkers and heavy drinkers at four US worksites. Zarkin et al (1998) using a combined sample of primeage workers from the 1991 and 1992 National Household Surveys on Drug Abuse (NHSDA) conclude that men who consume alcohol have approximately $7 \%$ higher wages than men who do not drink, and this estimated wage premium is approximately the same over a wide range of alcohol consumption. For women, the estimated alcohol use premium is approximately half as large as for men although this result is statistically insignificant.

\subsection{Smoking}

Smoking is now identified as a major cause of heart disease, stroke, several different forms of cancer and a wide variety of other health problems (Doll et al 1986; Mattsom et al 1987). Peto et al (1992) estimated that, during the 1990s tobacco use will be the largest single cause of premature death in developed countries causing approximately $30 \%$ of all deaths between the ages of 35 and 69. In 1990, Australia ranked $8^{\text {th }}$ highest among the 20 leading world consumers of manufactured cigarettes with an annual average consumption of 2,100 cigarettes per person (Commonwealth Department of Human Services and Health 1994).

If a cigarette smoker commences smoking as a teenager half of them are predicted to die due to tobacco related illness by middle or old age. Cancers may begin to occur in people aged in their 30s if they have been smoking for 15-20 years (Peto et al 1994; Holman et al 1988). Manning et al (1991) estimate that smoking reduces the life expectancy of a 20 year old by about 4.3 years or 7 minutes per cigarette. Smoking causes a build-up of fatty deposits in the artery walls and contributes to poor circulation, high blood pressure, heart disease and stroke. Smoking also paralyses and ultimately destroys the lining of the lungs and damages the air sacs through which oxygen passes into the blood in exchange for carbon monoxide. 
Toxic chemicals in cigarette smoking damage the lung capacity and clearance function, leading to increased coughs and respiratory infections among smokers (Brown et al 1987). "Pack-a-day" smokers when compared with people who have never smoked have 10 times the risk of lung cancer and twice the risk of heart disease (Savitz et al 1993). ${ }^{6}$

Employers may find that employees who smoke are less productive or more costly (or both) than those who do not and may therefore offer them lower wages. In comparison smokers are less fit than non-smokers, performing less well in both endurance and short term exercise. Smokers are slower and reach exhaustion earlier than nonsmokers. Smokers on average suffer poorer health than non-smokers and are more likely to miss work due to illness. Bush and Wooden (1995) using the Australian National Health survey data for $1989 / 90$ show smoking is consistently found to have a large and significant impact on absence from work. The probability of a male smoker being absent from work is estimated to be $66 \%$ greater than that for a male who has never smoked. For women, the corresponding figure is just 23\%. Ryan et al (1992) examines absenteeism among Telecom Australia's workforce. They estimated that during the 1991-1992 financial year smoking related absenteeism cost this employer $\$ 16.5$ million.

Since the 1980s there have been numerous studies that demonstrate harmful health effects in adult non-smokers from the inhalation of other people's tobacco smoke (passive smoking). These include irritation to the eyes, nose and throat, allergy, headache, nausea, decreased lung function, chronic airways disorders, lung cancer and emphysema (Winstanley et al 1995). A number of surveys (Hill 1986; Borland 1992; Mullins et al 1994; New South Wales Cancer Council 1990) show that a majority of smokers as well as nonsmokers believe that passive smoking is harmful to health and this awareness has increased over time. There have been a number of cases in Australia in which compensation has been awarded due to discomfort or disease caused by environmental tobacco smoke in the workplace (Winstanely 
et al 1995). If employers, co-workers or customers dislike smokers, discrimination against smokers leading to lower wages could result. As a consequence of passive smoke workplace smoking bans have become popular in Australia. Research has shown that bans bring about a reduction in numbers of cigarettes smoked on workdays (Borland et al 1990). However, bans may also result in workers taking time out for a cigarette outside the building which can be expensive for employers. One estimate is that a 'quick smoke' costs up to 25 minutes of productive time (Stickels 1994) ${ }^{7}$. This can also cause resentment among non-smoking staff who may feel that smokers are not working and may be a reason for employers to discriminate against them.

Levine et al (1997) using the National Longitudinal Survey of Youth data examine the effect of smoking on wages. They use a variety of approaches that control for differences in individual characteristics that may be correlated with both smoking and wages, include unobservable person-specific characteristics that are constant over time and also include unobservable characteristics that are constant within a family. Estimates from these alternative specifications indicate that smoking reduced wages by 4 to $8 \%$.

\subsection{Interactions}

Exposure to an alcoholic stimulus increases the desire to smoke and alcohol dependence constitutes a predictor of the need for tobacco. Research shows (Gulliver 1995; Burton and Tiffany 1997) that "smokers drink and drinkers smoke". Moreover the heaviest alcohol consumers are also the heaviest consumers of tobacco. Postulated mechanisms for the concurrent use of alcohol and tobacco are either drug may increase the rewarding effects of the other or either drug may decrease the unpleasant effects of the other.

Lee(1999) uses data from the Australian Twin Registry to analyze the impacts of genetic endowments and shared family background in the determination of the wage effects 
of drinking and smoking in the Australian labour market. In a wage equation model dummy variables are used to define drinkers and smokers ${ }^{8}$. Two alternative specifications are allowed for these being a fixed-effects model which is a within-twin estimation and a selectioneffects model which provides an explicit account of the family effects in the earnings equation. All models indicate that drinking leads to an increase in earnings relative to abstention whereas both past and present smoking habits have negative impacts on earnings.

This paper also estimates wage equations to analyze the impacts of both drinking and smoking. However, in difference to Lee(1999) we model the interaction of smoking with alcohol consumption by fitting separate models for smokers and nonsmokers. These models account for potential selectivity bias resulting from the decision to smoke and endogeneity arising from a potential causal relationship between earnings and alcohol consumption. Estimates are presented using data on males from the 1995 Australian National Health survey. This Survey is a large micro based survey with considerable economic and epidemiological detail. Section 2 provides a description of the survey and details characteristics of the data to be used. Section 3 details the empirical methodology. Regression results are presented and discussed in Section 4.

\section{DATA}

The Australian National Household survey is conducted every five years beginning in 1989/90. This paper will use data collected from the most recent survey conducted in 1995. The aim of this survey was to collect information about the health status of Australians, their use of health services and facilities and health-related aspects of their lifestyle. The survey covered urban and rural areas across all States and Territories of Australia, and included residents of both private and certain non-private dwellings. ${ }^{9}$ All households within sampled private dwellings were included in the survey along with a random sample of individuals 
residing in non-private dwellings. A household comprised a group of persons living together in a dwelling who considered themselves to be separate from other people in the dwelling and who made regular provision to take meals together. Non-Australians working in Australia, or in Australia as students or settlers, and their dependents were included in the survey scope ${ }^{10}$. Information for the survey was obtained by trained Australian Bureaus of Statistics (ABS) interviewers through personal interviews.

This survey contains usual data used to specify wage equations such as income, marital status, sex, age, education, hours worked, occupation classification, country of birth, year of arrival, family characteristics ${ }^{11}$, and state. Information relating to smoking include whether the individual smokes or is an ex-smoker and also included is the amount of alcohol consumed. A record was also kept on whether the consumption of alcohol during the survey week represented usual consumption patterns. Table 2.1 report the three categories of relative alcohol risk used by the Australian Bureau of Statistics (1996). These measures will be used in this paper.

Table 2.1: Relative Risk of Alcohol Consumption (Millilitres of Alcohol per day).

\begin{tabular}{lcc}
\hline Relative Risk & Male & Female \\
\hline Low & $<50$ M.L & $<25$ M.L \\
Medium & 50-75 M.L & $25-50$ M.L \\
High & $>75$ M.L & $>50$ M.L \\
\hline
\end{tabular}

Some under-reporting of alcohol consumption is expected to have occurred in both surveys. In particular, many consumers of alcohol, particularly those that consume large quantities are prone to deliberately or inadvertently underestimate the amount they have consumed. However it is considered that the results of the survey are a good indicator of relative consumption levels. Similar under-reporting of persons identified as current smokers is also expected to have occurred. Given it is only information on smoking categories rather 
than information on quantity of smoking, it is thought that the under reporting it not too severe. Other data on health-related actions used in this paper include the total amount of time spent exercising, degree of being over-weight as defined by body mass index ${ }^{12}$, the number of consultations with medical practitioners and a measure of whether the individual had a longterm medical problem. A full list of the variables used in this paper is given in Appendix A.

The 1995 survey contains 23,800 households. We restrict our sample to employed males between the ages of 15 and 65 . That is those who reported that in the preceding week to the survey they had worked in a job, business or farm for 25 hours or more or who had a job but were absent during that week. The measure of earnings used is income, before taxes and it is coded in categories which requires a method to deal with the top coded class. More details on the modelling of this problem is given in the empirical methodology section below. Both samples were further restricted to only those that responded that their main source of income was from a wage or salary from an employer. This leaves a total of 4,338 men

In the survey design the sample was split so that some sections of the survey were only administered to half the sample while the core questions were administered to all respondents. The 1/2 sub-sample included questions on education, alcohol consumption, private health insurance, women's health, and some questions concerning general health and well being. Another potential difficulty in this survey was that individuals were only asked to report their alcohol consumption for the 3 days preceding the day of the interview and then a weekly alcohol consumption was estimated by multiplying the 3 day total by $7 / 3$. Thus if they were surveyed on a Friday they would be responding as to their consumption on the preceding Tuesday, Wednesday, and Thursday. While those interviewed on a Monday would be reporting on their weekend consumption. Given that most interviews are conducted with approximately equal frequency Monday through Friday ${ }^{13}$ one can see that Mondays and Tuesdays are sampled $3 / 5$ of the time, Wednesdays and Saturdays are sampled 2/5 of the time 
and the other days $1 / 5$ of the time. In particular, this implies that Friday drinking would only be picked up in a Monday interview. In the earlier National Health survey conducted in 1989/90 individuals were asked to estimate their consumption by day of the week. An examination of this data indicated that alcohol consumption on weekends was quite different from weekday consumption ${ }^{14}$.

Using the 1989/90 data we generate an estimate for the total weekly alcohol consumption that accounted for the day of the interview. We used the reported consumption in the $1989 / 90$ survey for three consecutive days to estimate the total for the week. This was done for the 7 possible combinations of 3 consecutive days that could be observed in the 1995 survey. Using the 1989/90 data we fit 7 models where the dependent variable was total weekly alcohol consumption and the regressors were the consumption on the three consecutive days of the week as recorded in the 1995 survey. These models were estimated to compensate for the potential bias induced by zero values of the dependent variable. The predicted values from these regressions were used to estimate the weekly alcohol consumption for our analysis. This estimate was call Totall. In our analysis of the data we report results based on Total1 $^{15}$.

\section{EMPIRICAL METHODOLOGY}

The approach employed is to specify and estimate a model of wage determination by modifying a standard human capital health model where representative workers can to some extent influence their earnings by their choice of education, occupation and health. This function specifies earnings as a function of standard wage equation variables including experience, education, region, occupation, marital status and various measures of health.

In Section 1 we surveyed the medical literature which indicates that drinking and smoking have strong interactions. To allow for this interaction in this study smokers are 
treated as a separate group from nonsmokers and separate regressions are run for each group $^{16}$. To account for the possibility of endogeneity for choice of smoking a two-step Heckman correction to account for sample selection bias was used. This involved estimating a first stage probit equation which specifies a person's decision whether to smoker or not:

$$
\operatorname{Smos} d 1_{\mathrm{ij}}=Z_{\mathrm{ij}}^{\prime} \theta+\mathrm{v}_{\mathrm{ij}}=\pi_{\mathrm{ij}}+\mathrm{v}_{\mathrm{ij}}
$$

where if $\operatorname{Smosd} 1_{\mathrm{ij}} \geq 0$ the individual chooses to smoke, and if $S m o s d 1_{\mathrm{ij}}<0$ the individual chooses not to smoke. $Z_{\mathrm{ij}}$ is a list of explanatory variables for the decision to smoke ${ }^{17}$ and $\mathrm{v}_{\mathrm{ij}}$ is a normally distributed error term. From the estimate of the probit model, the density function and cumulative density function of a standard normally distributed variable, $\phi(\pi)$ and $\Phi(\pi)$ are constructed. The final step is to construct the Heckman's correction terms (or inverse Mills ratio) defined as

$$
\mathrm{IMR}^{\text {smoke }}=\phi(\pi) / \Phi(\pi) \text { and } \mathrm{IMR}^{\text {nonsmoke }}=\phi(\pi) /\{1-\Phi(\pi)\}
$$

from the density and distribution functions.

In the second stage wage equations separate wage equations are estimated that include the Heckman's correction term. They are of the form

$$
\begin{aligned}
& \ln w_{i}^{j}=\alpha K_{\mathrm{i}}+\beta X_{i}+\gamma H_{i}+\lambda \mathrm{IMR}_{\mathrm{i}}^{\mathrm{j}}+u_{i} ; \\
& i=1 \ldots N ; j=\text { nonsmoke or smoke }
\end{aligned}
$$

where the dependent variable is the logarithm of gross personal annual income and the index $i$ denotes the individuals. $K_{i}$ is a vector of variables of individual work characteristics including, potential work experience, education (past and current), occupation and number of jobs. $X_{i}$ is a vector of the individual's sociodemographic characteristics including marital status, number of children, country of birth, and geographical region. IMR ${ }_{\mathrm{i}}^{\mathrm{j}}$ is the appropriate inverse Mills ratio to include. 
The dependent variable is a categorical variable - gross personal income is grouped into 11 intervals from 'less than $\$ 5,000, ' \$ 5,000-\$ 9,999$ ', .., to 'greater than $\$ 60,000$ '. We estimate the means of the intervals provided for the income values given in the study by estimating the parameters of a log normal distribution for the data provided in the survey using an ordered probit likelihood. These estimates were calculated on the basis of sector (public, private). Once these estimates were obtained a series of log income midpoints were estimated for each range using the following equations:

$$
\hat{x}_{m i}=\hat{\sigma} \hat{z}_{m i}+\hat{\mu}
$$

where $\hat{z}_{m i}=\Phi^{-1}\left\{\frac{\Phi\left(z_{u i}\right)-\Phi\left(z_{l i}\right)}{2}\right\}, z_{u i}=\left(x_{u i}-\hat{\mu}\right) / \hat{\sigma}$, and $z_{l i}=\left(x_{l i}-\hat{\mu}\right) / \hat{\sigma}, x_{u i}$ is the log of the upper bound of the category $i, x_{l i}$ is the $\log$ of the lower bound of the category $i, \Phi$ is the Normal cumulative density function, $\Phi^{-1}$ is the inverse of the Normal cumulative density function (also referred to as the Probit function) and where $(\hat{\mu})$ and ( $\hat{\sigma})$ are the MLEs for each sector and gender combination.

$H_{i}$ is a vector of health characteristics of the individual. Included are total alcohol consumption and whether the consumption of alcohol over the period of the survey represents a usual pattern. In the medical literature a U-shaped relationship between alcohol consumption and risk of death from all causes has been identified. To account for the same type of relationship between drinking and earnings total alcohol consumption is entered into the equation as a quadratic. Also included are the number of long term medical conditions experienced by the individual (med) which reflects the overall health status of the individual. The variable $\mathrm{u}_{\mathrm{i}}$ represents the error term assumed to be distributed independently between individuals with constant variance and zero mean.

In addition in can be argued that the variable representing the amount of alcohol consumed may be endogenous and jointly determined along with income. As a result 
estimation by OLS could introduce simultaneous equation bias. Hence, the equation is estimated as a simultaneous equation model with selectivity bias (see Lee, Maddala and Trost 1980; Greene 1998). A reduced form equation for total consumption and total consumption squared are estimated. These equations include variables in the wage equation and are identified by a number of other variables including a set of country of birth variables, total amount of time exercised, a set of dummy variables which measure body mass index, a variable that measures the number of doctor visits and a set of state dummy variables. The predictions from these set of equations are then used as instrumental variables ${ }^{18}$.

\section{DISCUSSION}

The probit estimates of the smoking decision are reported in Appendix B. These probit estimates are used to generate values for the inverse Mills ratio for each observation in the sample as described in (3.2). These estimated inverse Mills ratios are then included in the wage equation for smokers and nonsmokers in order to correct for selection bias. Log wage equation estimates by smoking status are reported in Appendix C. These were estimated as described in Section 3 and use instrumental variables to allow for the potential endogeneity between wages and alcohol consumption.

The estimated Mills ratio coefficients are significant for nonsmokers but insignificant for smokers. Concave wage profiles (positive coefficient on experience and a negative one on experience squared) are found in each regression. For both regressions urban residence, married; education and occupation dummies are also significant. In addition, the number of long-term medical conditions is also significant in both regressions. However, in terms of alcohol consumption only in the case of nonsmokers do we find evidence for a $\bigcup$ shaped relationship. For smokers neither the linear or quadratic terms is significant. 
Calculating the turning point of the quadratic alcohol consumption for non-smokers gives a value of 44.3 (ml.of alcohol per day) which lies in the low risk drinking range of Table 2.1. This result is similar to numerous other studies that have examined the relation between alcohol consumption and wages (eg. Heien 1996; French and Zarkin 1995; Zarkin et al 1998). That is drinking is more beneficial for low/moderate drinkers in terms of wages than to either abstainers or heavy drinkers. The striking difference in this paper is that by examining smokers (who also tend to be the heaviest consumers of alcohol Gulliver 1995; Burton and Tiffany 1997 ) we find no significant relation between alcohol consumption and wages. Thus we confirm the medical literature which finds that these interactions are important. We also conclude that only through the simultaneous consideration of smoking and drinking can one establish their separate effects.

The results of this study can be used as further justification that the promotion of healthy activities can lead to increasing social welfare through increases in productivity. The arguments based on reduction in mortality and morbidity are well defined in the literature. There is a long tradition in the study of health factors on the productivity of the labour force in developing countries (Strauss and Thomas 1998) and thus there should be no surprise that increases in public health of a developed economy can produce benefits as well. 


\section{Appendix A: List of Variables}

\section{Variables}

Income

Linc: gross personal income where main source of income is wages

Occupation

Occupation1: Managers and Administrators

Occupation2: Professionals

Occupation3: Para-Professionals

Occupation4: Tradepersons

Occupation5: Clerks

Occupation6: Salepersons and Personal Service Workers

Occupation7: Plant and Machine Operators and drivers

Occupation8: Labourers and Related Workers

Nojobd1: number of jobs defined as one or more than one Part-time: if work less than 40 hours

Cap: reside in a capital city

\section{Education}

Ed1: higher degree, post-graduate diploma and bachelor degree

Ed2: skilled and basic vocational

Ed3: undergraduate diploma and associate diploma

Ed4: educational qualification inadequately defined

Ed5: no higher qualifications

Current-Study: Undertaking post-school study

\section{Number of Children}

nc0t4: number of children less than 4

nc5t9: number of children between 5 and 9

nc10t14: number of children between 10 and 14

nc15t19: number of children between 15 and 19

\section{Relationships}

Md1: married, defacto

Md2: separated, divorced or widowed

Md3: never married

Frd1: husband or wife with dependent children

Frd2: husband or wife without dependent children

Frd3: single parent with dependent children

Frd4: single parent without dependent children

Frd5: eldest of 2 or more related persons

Frd6: child(ren) aged $<15$ or child(ren) aged 15-20 who are full time students

Frd7: Other relatives aged $<15$ or aged 15-20 who are full time students

Frd8: Other son/daughter of any age

Frd9: Other relatives of family head

Frd10: Single person with non-relatives

Frd11: Single person living alone

\section{Country of Birth}

Cob1: Australia, New Zealand

Cob2: UK, Ireland

Cob3: Italy, Greece, Other Southern Europe, Western Europe, Other Europe, USSR, Baltic 
Cob4: Middle East

Cob5: Vietnam, Other Southeast Asia, Northeast Asia

Cob6: All Other

Exercise

Timeex: total time spent doing physical exercise undertaken for recreation, sport or health/fitness purposes during the two weeks prior to the interview.

Smoking

Smosd1: current smoker - occasional, regular

Nsmos: nonsmoker and ex-smoker

Weight

Body mass index (BMI) was calculated as weight divided by the square of height

D1: underweight, bmi $<20$

D2: Acceptable weight, bmi 20-25

D3: overweight, bmi $>25-30$

D4: obese, bmi $>30$

Drinking

Total1 in which total alcohol consumption adjusted for day of week as described in Section 2. Never: have never drunk alcohol

Doctor Visits

Numdoc: number of doctor visits in the 2 weeks prior to survey 
Appendix B: Probit Estimates of the smoking decision

Dependent variable is Smoking

\begin{tabular}{|c|c|c|c|c|c|}
\hline Variable & Coefficient & Standard Error & t ratio & $p$ value & Mean of Variable \\
\hline Constant & 0.356213 & 0.093536 & 3.808000 & 0.000100 & 1.000000 \\
\hline NAGE & 0.005137 & 0.004765 & 1.078000 & 0.281000 & 36.688912 \\
\hline NAGE2 & -0.000100 & 0.000060 & -1.680000 & 0.093000 & 1470.544500 \\
\hline NOJOBD1 & -0.039330 & 0.025671 & -1.532000 & 0.125500 & 0.070539 \\
\hline CAP & 0.043461 & 0.020149 & 2.157000 & 0.031000 & 0.545643 \\
\hline ED1 & -0.209179 & 0.019446 & -10.757000 & 0.000000 & 0.175888 \\
\hline ED2 & -0.026051 & 0.016064 & -1.622000 & 0.104900 & 0.283541 \\
\hline ED3 & -0.088835 & 0.022989 & -3.864000 & 0.000100 & 0.104195 \\
\hline ED4 & -0.032357 & 0.088749 & -0.365000 & 0.715400 & 0.005533 \\
\hline COB2 & 0.018896 & 0.023568 & 0.802000 & 0.422700 & 0.089442 \\
\hline COB3 & -0.001161 & 0.028703 & -0.040000 & 0.967700 & 0.059935 \\
\hline COB4 & 0.180091 & 0.099520 & 1.810000 & 0.070400 & 0.004380 \\
\hline COB5 & -0.057793 & 0.032942 & -1.754000 & 0.079400 & 0.044030 \\
\hline COB6 & -0.053245 & 0.041420 & -1.286000 & 0.198600 & 0.026049 \\
\hline MED & 0.177094 & 0.029155 & 6.074000 & 0.000000 & 0.054172 \\
\hline NC0T4 & 0.001476 & 0.015296 & 0.096000 & 0.923100 & 0.239281 \\
\hline NC5T9 & -0.021034 & 0.014301 & -1.471000 & 0.141400 & 0.225680 \\
\hline NC10T14 & -0.028155 & 0.015611 & -1.804000 & 0.071300 & 0.217151 \\
\hline NC15T19 & -0.034093 & 0.016574 & -2.057000 & 0.039700 & 0.154680 \\
\hline NUMDOC & 0.015603 & 0.012183 & 1.281000 & 0.200300 & 0.206547 \\
\hline FRD3 & -0.046611 & 0.022465 & -2.075000 & 0.038000 & 0.300830 \\
\hline FRD5 & 0.110346 & 0.082879 & 1.331000 & 0.183100 & -0.002305 \\
\hline FRD6 & -0.118148 & 0.068931 & -1.714000 & 0.086500 & 0.000692 \\
\hline FRD7 & 0.125418 & 0.084906 & 1.477000 & 0.139600 & -0.002766 \\
\hline FRD8 & -0.100551 & 0.123158 & -0.816000 & 0.414200 & -0.005763 \\
\hline FRD10 & -0.070684 & 0.028167 & -2.509000 & 0.012100 & 0.117566 \\
\hline FRD11 & -0.010064 & 0.066727 & -0.151000 & 0.880100 & 0.001153 \\
\hline FRD12 & 0.076859 & 0.029943 & 2.567000 & 0.010300 & 0.071231 \\
\hline FRD13 & 0.053653 & 0.029182 & 1.839000 & 0.066000 & 0.074919 \\
\hline FRD14 & -0.096130 & 0.134638 & -0.714000 & 0.475200 & -0.006224 \\
\hline D1 & 0.009941 & 0.024043 & 0.413000 & 0.679300 & 0.094283 \\
\hline D3 & -0.039563 & 0.014902 & -2.655000 & 0.007900 & 0.397879 \\
\hline D4 & -0.091204 & 0.022903 & -3.982000 & 0.000100 & 0.108575 \\
\hline TIMEEX & -0.000124 & 0.000022 & -5.690000 & 0.000000 & 365.956430 \\
\hline TIMEEX2 & 0.000000 & 0.000000 & 4.677000 & 0.000000 & 443636.690000 \\
\hline STATED1 & -0.008342 & 0.031634 & -0.264000 & 0.792000 & 0.150530 \\
\hline STATED2 & -0.036106 & 0.030258 & -1.193000 & 0.232800 & 0.245966 \\
\hline STATED3 & 0.043398 & 0.028374 & 1.529000 & 0.126100 & 0.123098 \\
\hline STATED4 & -0.044675 & 0.031254 & -1.429000 & 0.152900 & 0.161826 \\
\hline STATED5 & -0.038614 & 0.033799 & -1.142000 & 0.253300 & 0.098663 \\
\hline STATED6 & -0.016767 & 0.039034 & -0.430000 & 0.667500 & 0.042185 \\
\hline STATED7 & -0.012205 & 0.031456 & -0.388000 & 0.698000 & 0.079991 \\
\hline
\end{tabular}


Appendix C Estimates for Log Wages

Smokers Dependent Variable is Total1

\begin{tabular}{|l|r|r|r|r|r|}
\hline Variable & Coefficient & Standard Error & $t$ ratio & $p$ value & $\begin{array}{l}\text { Mean of } \\
\text { Variable }\end{array}$ \\
\hline Constant & 9.934889 & 0.142396 & 69.770000 & 0.000000 & 1.000000 \\
\hline E1 & 0.020495 & 0.005540 & 3.700000 & 0.000200 & 15.784148 \\
\hline E2 & -0.000376 & 0.000140 & -2.679000 & 0.007400 & 360.409360 \\
\hline NOJOBD1 & 0.022453 & 0.065456 & 0.343000 & 0.731600 & 0.058179 \\
\hline HD2 & 0.016636 & 0.032702 & 0.509000 & 0.611000 & 0.549747 \\
\hline CAP & 0.343429 & 0.086998 & 3.948000 & 0.000100 & 0.072513 \\
\hline ED1 & 0.076071 & 0.036288 & 2.096000 & 0.036100 & 0.314503 \\
\hline ED2 & 0.159607 & 0.057964 & 2.754000 & 0.005900 & 0.084317 \\
\hline ED3 & 0.100662 & 0.193192 & 0.521000 & 0.602300 & 0.005902 \\
\hline ED4 & -0.068839 & 0.124202 & -0.554000 & 0.579400 & 0.089376 \\
\hline MED & -0.190299 & 0.032493 & -5.857000 & 0.000000 & 0.289207 \\
\hline MD1 & 0.160421 & 0.044777 & 3.583000 & 0.000300 & 0.622260 \\
\hline MD2 & 0.081340 & 0.065036 & 1.251000 & 0.211000 & 0.073356 \\
\hline TOTAL1 & -0.001163 & 0.001424 & -0.817000 & 0.414100 & 187.749950 \\
\hline TOTAL12 & 0.000003 & 0.000003 & 1.057000 & 0.290500 & 67245.707000 \\
\hline NEVER & 0.014363 & 0.143416 & 0.100000 & 0.920200 & 0.016020 \\
\hline NC0T4 & -0.023265 & 0.029375 & -0.792000 & 0.428300 & 0.267285 \\
\hline NC5T9 & -0.039887 & 0.031444 & -1.269000 & 0.204600 & 0.211636 \\
\hline NC10T14 & -0.025782 & 0.039188 & -0.658000 & 0.510600 & 0.176223 \\
\hline NC15T19 & -0.055693 & 0.045257 & -1.231000 & 0.218500 & 0.111298 \\
\hline OCCD1 & 0.368159 & 0.068595 & 5.367000 & 0.000000 & 0.069140 \\
\hline OCCD2 & 0.286274 & 0.073456 & 3.897000 & 0.000100 & 0.072513 \\
\hline OCCD3 & 0.287230 & 0.072838 & 3.943000 & 0.000100 & 0.058179 \\
\hline OCCD4 & 0.068379 & 0.047773 & 1.431000 & 0.152300 & 0.268971 \\
\hline OCCD5 & 0.169462 & 0.063598 & 2.665000 & 0.007700 & 0.081788 \\
\hline OCCD6 & 0.174304 & 0.062233 & 2.801000 & 0.005100 & 0.085160 \\
\hline OCCD7 & 0.156925 & 0.050069 & 3.134000 & 0.001700 & 0.161046 \\
\hline LAMBDA & -0.050426 & 0.094753 & -0.532000 & 0.594600 & 1.127313 \\
\hline
\end{tabular}


Nonsmokers: Dependent variable is Total1

\begin{tabular}{|c|c|c|c|c|c|}
\hline Variable & Coefficient & Standard Error & t ratio & $p$ value & $\begin{array}{l}\text { Mean of } \\
\text { Variable }\end{array}$ \\
\hline Constant & 9.361616 & 0.096284 & 97.229000 & 0.000000 & 1.000000 \\
\hline E1 & 0.028831 & 0.003861 & 7.467000 & 0.000000 & 17.898319 \\
\hline E2 & -0.000505 & 0.000094 & -5.380000 & 0.000000 & 445.527200 \\
\hline NOJOBD1 & -0.030656 & 0.039506 & -0.776000 & 0.437800 & 0.075190 \\
\hline HD2 & 0.028831 & 0.022597 & 1.276000 & 0.202000 & 0.544099 \\
\hline CAP & 0.300855 & 0.046840 & 6.423000 & 0.000000 & 0.214784 \\
\hline ED1 & 0.084394 & 0.026812 & 3.148000 & 0.001600 & 0.271891 \\
\hline ED2 & 0.141002 & 0.038501 & 3.662000 & 0.000300 & 0.111675 \\
\hline ED3 & 0.435040 & 0.142508 & 3.053000 & 0.002300 & 0.005393 \\
\hline ED4 & -0.247240 & 0.154304 & -1.602000 & 0.109100 & 0.040926 \\
\hline MED & -0.145267 & 0.022826 & -6.364000 & 0.000000 & 0.286168 \\
\hline MD1 & 0.110717 & 0.036573 & 3.027000 & 0.002500 & 0.706218 \\
\hline MD2 & -0.042886 & 0.056305 & -0.762000 & 0.446300 & 0.052982 \\
\hline TOTAL1 & 0.005659 & 0.001677 & 3.374000 & 0.000700 & 140.498890 \\
\hline TOTAL12 & -0.000009 & 0.000004 & -2.321000 & 0.020300 & 44844.293000 \\
\hline NEVER & 0.271843 & 0.088081 & 3.086000 & 0.002000 & 0.050127 \\
\hline NCOT4 & 0.009808 & 0.020968 & 0.468000 & 0.639900 & 0.228744 \\
\hline NC5T9 & -0.010603 & 0.020183 & -0.525000 & 0.599400 & 0.230964 \\
\hline NC10T14 & 0.017406 & 0.020908 & 0.833000 & 0.405100 & 0.232551 \\
\hline NC15T19 & -0.028666 & 0.024592 & -1.166000 & 0.243700 & 0.171003 \\
\hline OCCD1 & 0.328346 & 0.056222 & 5.840000 & 0.000000 & 0.120558 \\
\hline OCCD2 & 0.287520 & 0.046135 & 6.232000 & 0.000000 & 0.197018 \\
\hline OCCD3 & 0.249754 & 0.049148 & 5.082000 & 0.000000 & 0.080266 \\
\hline OCCD4 & 0.084715 & 0.038368 & 2.208000 & 0.027200 & 0.212563 \\
\hline OCCD5 & 0.150958 & 0.044876 & 3.364000 & 0.000800 & 0.096129 \\
\hline OCCD6 & 0.084281 & 0.047997 & 1.756000 & 0.079100 & 0.085025 \\
\hline OCCD7 & 0.101888 & 0.046034 & 2.213000 & 0.026900 & 0.095178 \\
\hline LAMBDA & 0.184826 & 0.104980 & 1.761000 & 0.078300 & 0.424173 \\
\hline
\end{tabular}




\section{References}

American Council on Science and Health (ACSH) 1999, Moderate Alcohol Consumption and Health, prepared by K. Meister.

American Psychiatric Association 1980, Diagnostic and Statistical Manual of Mental Disorders, $3^{\text {rd }}$ edition, American Psychiatric Association, Washington DC

American Psychiatric Association 1987, Diagnostic and Statistical Manual of Mental Disorders, $3^{\text {rd }}$ edition revised, American Psychiatric Association, Washington DC

Australian Bureau of Statistics (ABS), 1996, 1995 National Health Survey User's Guide Australia, ABS Catalogue No 4363.0, Australian Government Publishing Service.

Barrett, G. 1999, "The Effect of Alcohol Consumption on Earnings," mimeo University of New South Wales.

Baum-Baicker, C. 1985, "The Psychological Benefits of Moderate Alcohol Consumption: A Review of the literature," Drug and Alcohol Dependence, 15, 305-22.

Berger, M. and Leigh, P. 1988, "The Effect of Alcohol Use on Wages," Applied Economics, 20, 1343-1351.

Borland, R. 1992, "Changes in prevalence of and attitudes to restrictions on smoking in the workplace among indoor workers in the state of Victoria, Australia, 1988-90", Tobacco Control, 1, 19-24.

Borland, R., Chapman, S., Owen, N. and Hill D. 1990, "Effects of workplace bans on cigarette consumption", American Journal of Public Health 80, 178-180.

Brown, R., Pinkerton, R. and Tuttle, M. 1987, "Respiratory infections in smokers", American Family Physician, 36, 133-140.

Burton, S. and Tiffany, S. 1997, "The effects of alcohol consumption on craving to smoke", Addiction, 92, 15-26.

Bush R. and Wooden, M. 1995, "Smoking and absence from work: Australian evidence," Social Sciences and Medicine, 41, 437-46.

Coate, D. 1993, "Moderate drinking and coronary heart disease mortality: evidence from NHANES I and the NHANES I follow-up," American Journal of Public Health 83, 888-890.

Commonwealth Department of Human Services and Health 1994, Better health outcomes for Australians. National goals, targets and strategies for better health outcomes into the next century. Canberra: Australian Government Publishing Service.

DeLabry, L., Glynn, R., Levenson, R. Hermos, M., LoCastro, J. and Vokonas, P. 1992, "Alcohol Consumption and Mortality in an American Male population: Recovering the U-shaped Curve findings for a Normative aging study," Journal of Studies on Alcohol, 53, 25-32.

Doll, R. 1986, "Tobacco: an overview of health effects", IARC Scientific Publications, 74, 11-22.

French, M. and Zarkin G. 1995, "Is moderate Alcohol Use related to Wages? Evidence from four worksites," Journal of Health Economics, 14, 319-44.

Frezza, M., di Padova, C., Pozzato, G., Terpin, M., Baraona, E., Lieber, C.S. 1990, "High blood alcohol levels in women. The role of decreased gastric alcohol dehydrogenase activity and first-pass metabolism," New England Journal of Medicine, 322, 95-99.

Goist, K. C. Jr, Sutker, P. B. 1985, "Acute alcohol intoxication and body composition in women and men," Pharmacology, biochemistry and behavior, 22, 811-814.

Grossman, M. 1972, "On the Concept of Human Capital and the Demand for Health", Journal of Political Economy, 80, 223-255.

Greene, W.1998, Limdep Version 7.0 User's Manual,Econometric Software Inc, NY. 
Gulliver, S. 1995, "Interrelationships of smoking and alcohol dependence, use and urges to use", Journal of Studies on Alcohol, 56, 202-206.

Hamilton, V. and Hamilton, B. 1997, "Alcohol and Earnings: Does drinking Yield a Wage Premium," Canadian Journal of Economics, 30, 135-51.

Heien, D. 1996, "Do Drinkers earn Less?” Southern Economic Journal, 63, 60-68.

Hill, D. 1986, "Public Opinion about Smoking in Restaurants and at Work," Medical Journal of Australia, 145, 657-658.

Holman, C., Armstrong, B., Arias, L., Martin, C., Hatton, W., Hayward, L., Salmon, M., Shean, R. and Waddell, V. 1988, The quantification of drug caused morbidity and mortality in Australia. Canberra: Commonwealth Department of community Services and Health.

Jackson, R., Scragg, R. and Beaglehole, R. 1991, "Alcohol consumption and risk of coronary heart disease," British Medical Journal, 303, 211-216.

Klatsky, A., Armstrong, M. and Friedman, G. 1990, "Risk of Cardiovascular Mortality in Alcoholic Drinkers, Ex-drinkers and Nondrinkers," The American Journal of Cardiology, November, 1237-42.

Lee, L., Maddala, G. S. and Trost, R.P. 1980, “Asymptotic Covariance Matrices of Two Stage Probit and Two Stage Tobit Methods for Simultaneous Models with Selectivity," Econometrica, 48, 491-504.

Lee, Y. 1999, "Wage Effects of Drinking and Smoking: An analysis using Australian Twins Data," University of Western Australia Working Paper, 99-22.

Levine, P. B., Gustafson, T. A. and Velenchik, A. D. 1997, "More bad news for smokers? The effects of Cigarette smoking on wages," Industrial and Labor Relations Review, 50, 493-509.

London, W., Whelan, E. and Golaine, A. 1996, Cigarettes: What The Warning Label Doesn't Tell You, American Council on Science and Health, New York.

Manning, W. G., Keeler, E. B., Newhouse, J. P., Sloss, E. M. and Wasserman, J. 1991, The Costs of Poor Health Habits. Cambridge: Harvard University Press.

Mattsom, M. E., Pollack, E. S. and Cullen, J. W. 1987, "What are the odds that smoking will kill you?" American Journal of Public Health, 77, 425-431.

Moore, R.D., Pearson, T. A. 1986, "Moderate alcohol consumption and coronary heart disease. A review," Medicine, 65, 242-267.

Mullahy, J. and Sindelar, J.L. 1993, “Alcoholism, Work, and Income," Journal-of-LaborEconomics; 11, 494-520.

Mullahy, J. and Sindelar, J.L. 1996, "Employment, unemployment and problem drinking," Journal of Health Economics, 15, 409-434.

Mullins, R., and Borland, R. 1994, "How bothered are people by environmental smoke?" Medical Journal of Australia 160 (9), 585-6.

National Health Survey 1995, Summary of Results Australia ABS 4364.0

National Institute on Alcohol Abuse and Alcoholism 1997, Ninth Special Report to the US Congress on Alcohol and Health, US Department of Health and Human Services, Rockville, MD.

National Institute on Alcohol Abuse and Alcoholism 1990, "Alcohol and women," Alcohol Alert No. 10.

National Institute on Alcohol Abuse and Alcoholism 1997a, "Alcohol metabolism," Alcohol Alert No. 35.

National Institute on Alcohol Abuse and Alcoholism 1998, "Alcohol and the elderly," Alcohol Alert No. 40. 
National Health and Medical Research Council (NHMRC) 1992, Is There a Safe Level of Daily Consumption of Alcohol for Men and Women?, Australian Government Printing Service, Canberra.

New South Wales Cancer Council Public Opinion Survey 1990, Smoking in Restaurants Sydney: New South Wales Cancer Council.

Pearson, T.A. 1996, "Alcohol and Heart Disease," Circulation, 94, 3023-3025.

Peto, R., Lopez, A. D., Boreham, J., Thun, M. and Heath, C. Jr 1992, "Mortality from tobacco in developed countries: indirect estimation from national vital statistics", Lancet, 339, 1268-1278.

Peto, R., Lopez, A. D., Boreham, J., Thun, M. and Heath, C. Jr 1994, Mortality from smoking in developed countries 1950-2000: indirect estimation from national vital statistics. Oxford: Oxford University Press.

Razay, G., Heaton, K., Bolton, C., and Hughes, A. 1992, "Alcohol Consumption and its relation to Cardiovascular Risk Factors in British Women," British Medical Journal, January 11, 80-83.

Rimm, E., Giovannucci, E., Willett, W., Colditz, G. Ascherio, A. Rosner, B., and Stamper, M. 1991, "Prospective Study of Alcohol Consumption and Risk of Coronary Disease in Men," The Lancet, August 24, 464-68.

Rimm, E., Klatsky, A., Grobbee, D., Stampfer, M. 1996, "Review of moderate alcohol consumption and reduced risk of coronary heart disease: is the effect due to beer, wine or spirits?," British Medical Journal, 731-736.

Ryan, J., Zwerling, C. and Orav E. J. 1992, Occupational Risks associated with cigarette smoking: a prospective study," American Journal of Public Health 82, 29-32.

Savitz, D., Harris, R. and Brownson, R. 1993, "Methods in chronic disease epidemiology," in Chronic Disease Epidemiology and Control by Brownson, R., Remington, P. and Davis, J. eds, Washington, DC: American Public Health Association.

Stickels, G. 1994, "Lost output on the smoke threshold," Business Review Weekly, September 26, 85-86.

Strauss, J. and Thomas, D. (1998), "Health, Nutrition and Economic Development," Journal of Economic Literature, 36, 766-817.

Winstanely, M., Woodward, S. and Walker, N. 1995, Tobacco in Australia Facts and Issues 1995, Victorian smoking and Health program Australia.

Zarkin, G. A.,, French, M. T., Mroz, T. and Bray, J. (1998), "Alcohol use and wages: new results from the National Household Survey on Drug Abuse," Journal of Health Economics, 17, 53-68. 


\section{ENDNOTES}

${ }^{1}$ A standard drink consists of one 12-ounce can of beer, one 5-ounce glass of wine, or a mixed drink containing 1.5 ounces of 80 proof spirits.

${ }^{2}$ Note that the pattern of drinking is also very important. The pattern of drinking that includes episodes of heavy intake (i.e. weekend splurges and weekday abstinence ) even if the individual's total weekly alcohol intake is within the limits of moderation can be very harmful (ACSH 1999).

${ }^{3}$ Among middle-aged and elderly people moderate drinkers have lower mortality rates than do abstainers which has been shown to be largely due to the protective effect of alcohol against coronary heart disease. Among younger people, that is, men who have not reached their 40s and premenopausal women no beneficial effect of moderate drinking on mortality has been demonstrated ( ACSH 1999).

${ }^{4}$ Alcoholism is used to summarize both the "alcohol dependence" and "alcohol abuse" disorders as defined by the American Psychiatric Association (1980,1987).

${ }^{5}$ Problem drinking is generally defined as heavy drinking and also the diagnosis of an alcohol-related disorder, alcohol abuse and/or dependence.

${ }^{6}$ While it is possible that smoking just a few cigarettes a day might not present a significant health risk to most people there is evidence to suggest that there are relatively few smokers who limit their smoking that much. It is estimated that the vast majority of current smokers smoke more than 15 cigarettes a day (London et al 1996)

${ }^{7}$ Employees get distracted by thinking about having a cigarette, three or four minutes go on closing up the current work task, ten minutes are spent smoking the cigarette, and seven or eight minutes are spent regaining the momentum.

${ }^{8}$ Drinkers are defined as those who drink liquor, beer or wine once or twice a week or more, and non-drinkers as those who drink less. Smoking is separated into 3 categories these being non-smokers who have never smoked cigarettes during their lifetime, smokers who consumes at least one cigarette on average a day and ex-smokers. 9 A private dwelling was defined as a house, flat, home unit, caravan, garage, tent and any other structure being used as a private place of residence at the time of the survey. Non-private dwellings included hotels and motels, hostels, boarding houses and caravan parks. Hospitals, nursing homes and convalescent homes were excluded from the scope and/or coverage of the survey, as were prisons, reformatories and single quarters of military establishments. A supplementary sample of the Indigenous population was included to enhance the reliability of data.

${ }^{10}$ This excluded diplomatic personnel of overseas governments and Non-Australian members of their household; non-Australian service personnel stationed in Australia and their dependents and overseas visitors whose usual place of residence in outside Australia.

${ }^{11}$ Information on family characteristics includes the number and age of children in the household and the number of hours the partner works.

${ }^{12}$ Body mass index (BMI) is calculated as weight divided by the square of height. The National Health and Medical Research Council define an individual whose bmi is $<20$ as being underweight, bmi $>25-30$ as being overweight, bmi $>30$ as being obese and bmi between 20-25 as being of acceptable weight.

${ }^{13} \mathrm{~A}$ frequency count of the days of the week on which the survey was asked revealed that Saturday and Sunday interviews were quite rare.

${ }^{14}$ To determine the influence of the change in the question for 1995 we simulated a series of results for the 1989/90 data based on the equivalent total alcohol consumption that may have been generated if the 1995 method was used in 1989/90. Thus each response for 1989/90 was randomly given a day of the interview based on the distribution of the days of the interview as observed in the 1995 survey (mostly weekdays with a few weekend days). Then we repeated this simulated value 100 times for each household. The ratio of the simulated weekly total and the actual reported total was computed for each interview day and by gender over all the replications of the 19,170 adults in the 1989/90 survey. It was found that the method used in 1995 will under report the consumption by .80 for men and .73 for women when using the distribution of interview days of the week from the 1995 survey. This average ratio varied from 1.03 for men surveyed on a Monday to .45 for women interviewed on a Friday.

${ }^{15}$ Results based on the estimate provided in the survey give similar results and are available on request.

${ }^{16}$ Ex-smokers were included with non-smokers. Since the dummy variable for this group was not significant they were not distinguished from non-smokers.

${ }^{17}$ The variables are similar to those to be defined for the wage equation except for the exclusion of the smoking variables and instead of the inclusion of the married/defacto and divorced/widowed/separated dummy variables a more detailed set of family relationship variables were included. 
${ }^{18}$ Note though as in conventional simultaneous equations it is necessary to use the original data, not the predicted values when computing the estimate of the disturbance variance. The estimates of these equations are not of primary interest here and are available on request. 